\title{
Reconstructing Biogeochemical Cycles During and After the Ediacaran DOUNCE (Shuram) Excursion
}

\author{
ZHEYU TIAN $^{1}$, GRAHAM A SHIELDS ${ }^{1}$, YING
} $\mathrm{ZHOU}^{1}$, MAOYAN ZHU ${ }^{2}$, MIAO LU ${ }^{2}$

${ }^{1}$ Department of Earth Sciences, University College London, WC1E 6BS, London, UK, z.tian.17@ucl.ac.uk

${ }^{2}$ State Key Laboratory of Palaeobiology and Stratigraphy, Nanjing Institute of Geology and Palaeontology, Chinese Academy of Sciences, Nanjing 210008, China,

myzhu@nigpas.ac.cn

The Ediacaran Shuram Excursion ( $\sim 560 \mathrm{Ma}$ to $\sim 551 \mathrm{Ma})$ was a major negative $\delta^{13} \mathrm{C}$ excursion (as low as $-12 \%$ ) worldwide, which in China occurs in the upper Doushantuo Formation and is referred to as DOUNCE [1]. This event is proposed to be a consequence of ocean oxygenation and marks a faunal change from microfauna to megascopic Ediacaran Biota [1,2]. This makes it a key time interval to understand the relationship between marine environmental changes and early animal evolution.

Carbonate deposits occur widely in normal marine settings, making carbonate associated sulfate an ideal proxy material for understanding how ancient seawater sulfate $\delta^{34} \mathrm{~S}_{\mathrm{sw}}$ has changed over time [3]. CAS is also believed to be relatively resistant to later diagenetic alteration [3]. Aside from CAS, I carried out a detailed petrological study, elemental analyses, including REY, and uranium isotope studies of three sections: Lianghong, Sishang-Majiawan, and Qinglinkou section in South China, in order to understand marine environmental changes during that interval.

Stable isotope and elemental data indicate that these carbonate deposits are relatively well preserved. Existsin strontium isotope data [4] are consistent with increased chemical weathering through this time. Changes in $\mathrm{Mn}, \mathrm{Fe}$ contents, together with $\delta^{34} S_{\text {cas }}$ data, confirm that the DOUNCE and its aftermath experienced episodic redox changes. In summary, the emergence and decline of megascopic Ediacaran benthic fauna were tightly linked to marine environmental and weathering regime changes.

[1] Lu, Miao, et al. (2013). J. Precambrian Research 225: 86109. [2] ZHU, M. et al. (2017) J. Geological Magazine 154, 1187-1192. [3] MARENCO, P. et al. (2008). J. Chemical Geology 247, 124-132. [4] Cox, G.M., et al. (2020). J. Earth and Planetary Science Letters 446, 89-99. 